\title{
EdTech and the Review of Efficiency and Effectiveness in Higher Education
}

\author{
James Steele \\ Instructional Media Centre \\ Canberra College of Advanced Education
}

\begin{abstract}
Just before going to press with this edition of the Australian Journal of Educational Technology, the Commonwealth Tertiary Education Commission released its Review of Efficiency and Effectiveness in Higher Education. This article looks at the Review in terms of what it says about external studies and about the use of technology in higher education.
\end{abstract}

In August 1985 the Federal Government announced that it would ask the Commonwealth Tertiary Education Commission (CTEC) to carry out a review of efficiency and effectiveness in higher education in Australia. Among other things, the Review would examine:

- the potential for achieving better utilisation of existing resources especially through ... the application of new technologies; ... and

- further steps which could be taken to improve delivery of courses and reduce unnecessary duplication ... (CTEC, 1986, xv)

In October 1985, the Minister for Education, Senator Ryan, announced the membership of a Committee established to undertake the Review. The members of the Committee were Mr Hugh Hudson (Chairman of CTEC), Dr Graham Allen (Chairman of the Victorian Post-Secondary Education Commission), Mr Jack Barker (Director of the Ballarat College of Advanced Education), Professor Peter Karmel (Vice-Chancellor of the Australian National University) and Dr Brian Scott (Chairman of W. D. Scott International Development Consultants and Chairman of Management Frontiers). 
The Committee invited and received submissions, consulted with a number of bodies with some interest in the area, commissioned several studies (including a study of external studies in higher education undertaken for the Review by the Standing Committee on External Studies) and gathered additional information from other reports, statistics and reference materials from CTEC and other sources.

The Committee's report was released by Senator Ryan on 24 October 1986. According to Senator Ryan, the review found that there have been major improvements in the efficiency and effectiveness of Australian universities and colleges of advanced education over the past decade, and that higher education institutions had undergone major restructuring over the decade, allowing major economies of scale to be achieved (Ryan, 1986).

The overall scope of the Committee's Review is far greater than could be covered in an article of this size, and probably would not be of interest to readers of AJET anyway. Those who are interested in more details of the Committee's report should pick up a copy from their local AGPS Bookshop and read the original 291 pages! Since the Review was released only 4 days before the deadline for this issue of AJET this article will not be able to give a detailed response to the Review, and will concentrate on summarising those aspects of the Committee's report concerning education and technology and distance education, two areas which will be of greater interest to readers of AJET than some of the other areas covered by the Review.

\section{New technologies}

A disappointing aspect of the Committee's report is that there are no formal recommendations regarding the use of new technologies in higher education. There is some discussion in the Review about the role for new technology in tertiary teaching, but it has given no guidance to those who are involved in educational technology as to how they might proceed.

It might have been a little more helpful if the Committee had included its definition of "technology" in the report. The Australian Society of Educational Technology defines educational technology as the design application, evaluation and development of systems, methods and materials to improve the process of human learning (ASET, 1986, p11).

Obviously the Committee's definition of technology is narrower than ASET's, taking the more widely-held view that technology equals hardware. Unless educational technologists can convince people that technology is far more than equipment, no real progress in the wide use of new "technologies" in education will come about. Maybe it is time to surrender the title "technology" in all its forms when talking about 
improving learning, and substitute another word or other words which make the meaning far clearer to those who must be convinced of the benefits of investing in additional or alternative strategies designed to improve the efficiency and effectiveness of students' learning.

There are several aspects of the use of new technologies in higher education addressed by the Committee's report, covering teaching about new technologies, using new technologies in administration and using new technologies to assist or replace traditional methods of the delivery of education to students. It is this last area that is of interest here, and on this subject the Committee concludes that:

\begin{abstract}
Computing and communications technologies ... have considerable potential as aids in teaching and learning, particularly in distance education.
\end{abstract}

$$
\begin{aligned}
& \text { However, exaggerated and unduly optimistic expectations are sometimes held for } \\
& \text { the benefits which could be gained from more extensive use of these technologies. } \\
& \text { There is no clear evidence, either in Australia or in other countries, that they } \\
& \text { can reduce in any major way the resources required to achieve specific } \\
& \text { educational outcomes. Moreover, developments in this field tend to be } \\
& \text { expensive. Institutions should be encouraged to use new technologies } \\
& \text { where they are cost-effective and can be implemented within available } \\
& \text { funding levels. (CTEC, 1986, pp8-9. Stress in original) }
\end{aligned}
$$

Educational Technologists have a lot of work before them to convince powers that be that resources should be applied to the development of alternative "technologies" for the delivery of learning experiences to students. It appears from the Committee's report that its members believe that if there is to be change in education, such change should be incremental and evolutionary rather than radical. Possibly the Committee would have gained some benefit from the inclusion of additional members who were a little more removed from the system under review.

There is an unstated assumption in the Committee's report that the independence of the individual academic and (at least in the CAE and university sector) the institution is sacrosanct. In this circumstance, most new technologies are and will remain uneconomic for a public education system to implement effectively on any wide scale. This is not to say that learning experiences can be delivered more effectively with traditional "technologies" than can be the case with newer "technologies" - just that, under the present circumstances, it is cheaper to continue teaching using the existing structures of education than adding on newer ways of serving student needs. Obviously. The Committee cites part of the submission to it from the Treasury, which put the view that " ' ... The new technologies can 
only make a significant contribution to reducing the costs of higher education if they are used as a substitute for other factors of production in the production process' " (CTEC, 1986, p148).

As an aside, it is interesting to note Treasury's use of the production process analogy in its submission to the Committee. The reality of the $1980 \mathrm{~s}$ is that governments are being advised to see education as a production process - so many dollars input for a certain level of output, which one presumes represents educated people of some known quality. There are some in education who might like to take up this point with the Treasury.

But back to the point. Without a significant restructuring of the Australian tertiary education system, there will be no financial benefit to be had from the use of new technologies in that sector of education. Other areas outside education, not constrained by academic staff associations, CTECs, College Councils, University Senates and so on, will take up the new technologies with a commercial gleam in their eye. These commercially-oriented organisations will package learning materials in subjects where they think they can sell sufficient numbers of packages to turn a profit. The market for these packages initially will be institutions here and there, and possibly the students themselves. Eventually commercial suppliers may offer to teach students skills in particular areas without the need for the students to be involved with the more rigid structures of tertiary education, bypassing the traditional systems. There will be a drain of students from the traditional education system and into privately-run short courses which will use the latest technology as a lure.

Of course, this scenario does not describe the replacement of an existing system with an equivalent one - more the development of a different sort of educational institution more responsive to the needs of the community for access to new skills (training rather than education), and more able to turn out people trained (not necessarily educated) to suit the needs of industry for workers proficient in up-to-date methods. Such institutions will be very popular with students and with industry, and extremely unpopular with traditional educational institutions from which they will take students and eventually public funds. Just supposing Alan Bond decided that traditional educational institutions were unable, for whatever reason, to supply sufficient and appropriately educated graduates for particular purposes. Maybe he would see the commercial sense of setting up a private institution committed to satisfying the demand - for a particular product. It is also interesting in this context to note that Control Data Institute has just announced the placement of its 5000th "graduate" (The Australian, 4 November 1986, p25). 
The Committee's report also addresses the issue of the cost of educating students in areas where technology is constantly changing - in computing, for example. The Review quite rightly points out that the need to keep up with this sort of technological change adds to the expense of education, and accepts that it is not the fault of institutions that they cannot keep their equipment up to date. The Committee realises that additional resources must be allocated by government to allow institutions to replace obsolete equipment and repair unserviceable gear, and so recommends, but is silent on the solution to the problems institutions face in providing the additional plant necessary to keep higher education courses relevant to the needs of the modern world. If it is a fact of life that a more complex industrial society requires graduates with particular skills that only contact with ever-changing technology can provide, then the community must support the costs of providing the appropriate facilities or suffer the consequences. It may be that traditional educational institutions are not the most efficient and effective vehicles for providing the necessary facilities on their own, and if such institutions are to continue to provide graduates with relevant experience they may need to develop working relations with other institutions (educational and industrial) in order to provide students with access to suitable facilities. The Committee has addressed the issue of the need for educational institutions to consider sharing major items of equipment with other educational institutions (p139), but does not appear to have taken the idea further into the business sector.

This discussion of education in technology strays away from a consideration of educational technology, but it highlights the difficulty faced by those who would champion the cause of allocating more resources for the development of more effective methods of delivering learning experiences to students.

In essence, so-called educational technologists must simplify their arguments. Not because the arguments are simple (indeed they are not), but those with whom educational technologists must discuss the future of educational technology do not have the time nor the breadth of experience necessary easily to grasp the possibilities provided by the application of the fruits of the information revolution to education. Professionals in educational technology know that new 'technologies" can improve the efficiency and effectiveness of students' learning, provided the right tools are chosen.

Effective teaching at any level requires a combination of "good" teachers, adequate resources and motivated students. No doubt readers could add to this list, but it is included to support the argument that learning is not a simple process to which a number of different alternative strategies can be 
applied as direct replacements for each other with more or less equal outcomes. Teaching, the facilitation of learning, is a professional process requiring, among other things, a professional, resources and students. In the present system, it is the academic who provides the focus for the educational process in higher education in Australia. Given all the resources in the world, it is the academic who must marshal those resources into an effective educational experience for students to learn from. So it is with any technology - it is a tool to be used by the artisan, a science to be applied for a particular outcome or to satisfy a series of objectives, or a system to be applied as appropriate.

There seems to be a view in the Committee's report that advocates of the use of "new technologies" see them as an alternative to existing techniques. Ideally, "new technologies" could be alternatives to existing practices, but for reasons outlined elsewhere in this article, it is unlikely that such a course will become reality. The realists know that "new technologies" will only become used as adjuncts to existing practices. Of course, television and radio courses will not replace traditional lectures (video- and audiocassettes are more likely to, but won't either), but the thirst academics seem to have for the "time-shifted" broadcast television program seems to indicate that there is some redeeming value in video material for classroom use. The popularity of the integrated video camerarecorder set-ups also suggests that the moving image has a place in teaching.

The Committee has taken the view with regard to broadcast television that its educational use "especially as the sole medium of educational delivery, has been shown to have serious limitations ... " (CTEC, 1986 p151). Few "educational technologists" would disagree. The Committee has painted an extreme and simplified picture of the view taken by proponents of alternatives to traditional teaching methods, and one can only speculate on the reasons why this may be so. Possibly the perceived resource implications are scaring them away, or they have no real understanding of what the proponents of alternatives to traditional teaching methods are actually proposing. It may be that the industrial and structural implications of developing alternatives are seen as being too horrible to contemplate.

In reality, the key to the effective use of "technology" in higher education as it exists today is the individual academic. There must be effective staff development programs available for them to be able to develop their teaching skills, one part of which is how to use appropriate resources which may (or may not) be delivered by new technology. In another part of its report, the Committee expresses the belief that: 
all higher education institutions should give a clear priority to the determination of staff development policies and to the implementation of programs aimed at encouraging and providing opportunities for staff to use to the full their individual talents and to develop in ways which maximise the achievement of institutional goals. (CTEC, 1986, p181).

A part of such staff development programs should be the use of alternative teaching strategies which might include the appropriate use of new "technologies", like the photocopier, the home video camera recorder and the microcomputer. These are appropriate technologies accessible to individuals to use on their own, which fits in with the highly individual nature of the academic in higher education.

In an ideal world, where there were no existing prejudices and threatened empires, it might be different. It might be possible, with the application of as much resources (or even less, possibly) to develop strategies for the facilitation of learning which would result in a much more efficient and effective higher education system. But it won't happen.

Maybe there could be a Centre for Excellence in the Development of Resource Materials for use in Higher Education in Australia, a sort of Curriculum Development Centre for Universities and CAEs. It could not only produce relevant material in a range of media for a narrow audience (in depth), but could also act as a packager and distributor of materials from other tertiary institutions in Australia and abroad. Many institutions produce materials which have relevance beyond their own campus, but these products never gain wider distribution because of institutions' lack of access to expertise and the necessary resources to package and market ("publish"?) materials of the necessary quality and relevance.

The Centre could be supported in part by sales of materials to various institutions, and otherwise from grants for the production of specialised materials in areas of rapid growth where there is a need for rapid and effective dissemination of information to tertiary institutions across Australia.

Where complete packages were available, students could approach the Centre for enrolment in those courses, at a fee. Such courses could be taken as modules which could be used for credit in a number of different institutions, or marketed overseas. The face-to-face aspect of teaching in these particular courses could be handled initially in existing participating institutions, but as demand for the courses grow, individual study centres could be established under the direct control of the National Centre.

Just draw the line where your imagination ends. 


\section{External studies}

The Committee has recognised the importance of external studies or distance education as a means of meeting Government objectives, although it recognises that arrangements for the provision of external studies courses have developed without clear planning and coordination.

On an Open University model for Australia, the Committee reports that it "has considered carefully the possibility of a large centralised provider of external studies for Australia ... but is satisfied that this approach would not be the most appropriate form of provision in this country" (CTEC 1986, p224). Its reasons are mainly the cost and the impact of such an institution on existing distance education-providing institutions, as well as the educational benefits perceived to come from smaller course run by regional providers.

The Committee does, however, concede that there needs to be "substantial rationalisation and coordination" in the present system (CTEC, 1986, p224). It has recommended that CTEC takes on the responsibility for negotiating a restructured external education provider network with two types of providers: principal providers and specialist providers.

Principal providers are institutions or groups of institutions which have the facilities for course development, preparation and production and are able to provide a full external studies program. Examples of principal providers include Deakin University, University of New England, Darling Downs Institute of Advanced Education and a combination of the Western Australian College of Advanced Education, Murdoch University and Western Australian Institute of Technology external studies units as a Joint principal provider.

Specialist providers are those with special expertise or with a special relationship with some client group, or both. Such providers would provide specialist external studies courses in conjunction with a principal provider. Examples of the specialist providers proposed by the Committee include Macquarie University (in science courses), Tasmanian State Institute of Technology (because of its special relationship with a client group), Queensland Institute of Technology (in Law) and the Victorian College of Agriculture and Horticulture.

The Committee has suggested that some current suppliers of external studies should relinquish the role of providing such courses unless a case can be made for the provision of specialist courses. 


\section{EdTech and external studies}

In its discussion of the role of technology in external studies, the Committee has again been cautious in its approach. It emphasises that Australia should wait and see what happens overseas and use that experience as a guide "which avoids unnecessary and costly experimentation within Australia" (CTEC, 1986, p226). This approach substantiates the view that Australians are individualists in their approach, but it also indicates that such individualism is not necessarily by choice. No bureaucrat is going to be caught publicly supporting innovation. Let the enthusiasts get out there (within existing budgets, of course) and burn their fingers. If they succeed, the bureaucrats will be there beside them, saying how much the system encourages such innovation, and supports it, in principle. As every bureaucrat knows, support in principle is just another way of saying no money.

Only when (or if) support, resources and cooperation are put towards experimental applications of new techniques will Australians be able to make firmly-based decisions about what is effective in this environment and what is not. The poorly-resourced and unsupported applications now current are no basis upon which to judge the efficacy of new technologies in education.

\section{Summary}

The Review of Efficiency and Effectiveness in Higher Education has missed an ideal opportunity to look beyond current structures and practices in higher education in Australia today and provide some idea of the possibilities and indeed increased efficiencies which could come from alternatives to traditional modes of delivering education and from more inter-institutional cooperation. If it is worthwhile continuing with individual institutions developing and running external studies courses, why can't those same course packages (or at least elements of them, adapted to local conditions) be used more widely for on campus teaching across a number of institutions? How many Open University texts are used already in Australian tertiary institutions? Where is the mechanism for packaging and marketing home-grown products? What, one may ask, is CTEC doing on a practical level about facilitating the inter-institutional cooperation it proposes?

There are a number of quite significant barriers to overcome before there is the increase in efficiency and effectiveness of which the higher education sector in Australia is potentially capable. The Committee has not been bold enough to address these barriers in its Review, and does the community a disservice by failing to consider in sufficient depth alternative strategies for supporting student learning. 


\section{References}

Australian Society for Educational Technology (1986). Some information about ASET. Australian Journal of Educational Technology, 2(1), 11.

The Australian. Tuesday 4 November, 1986, p25. 5000th Graduate.

Commonwealth Tertiary Education Commission (1986). Review of Efficiency and Effectiveness in Higher Education. Canberra: AGPS.

Ryan, S. (1986). Efficiency and Effectiveness in Higher Education. Press Release M196/86, 24 October 1986.

Please cite as: Steele, J. (1986). EdTech and the Review of Efficiency and Effectiveness in Higher Education. Australian Journal of Educational

Technology, 2(2), 129-138. http:/ / www.ascilite.org.au/ajet/ajet2/ steele.html 